
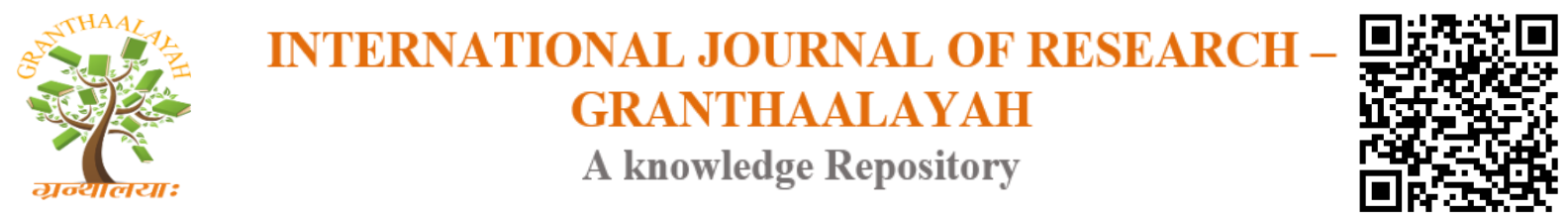

Science

\title{
INTERACTION STUDIES OF AMINO ACIDS IN AQUEOUS SODIUM BROMIDE SOLUTIONS AT DIFFERENT TEMPERATURE
}

\author{
Dr. Yasmin Akhtar ${ }^{* 1}$ \\ ${ }^{* 1}$ Al-Falah University, Dhauj, Faridabad, Haryana, India \\ ${ }^{* 1}$ Department of Chemistry, University of Tabuk, Tabuk, Saudi Arabia
}

\begin{abstract}
Densities, ultrasonic velocities and viscosities of L- Valine and L- Phenylalanine in aqueous sodium bromide $(0.00,0.025$ and 0.05$) \mathrm{m}$ solutions have been determined experimentally at 308 and $313 \mathrm{~K}$. The results obtained from density ultrasonic velocity and viscosity measurement have been used to calculate the apparent molal volume, $\phi_{\mathrm{v}}$, apparent molal, adiabatic compressibility $\phi_{\mathrm{Ks}}$, partial molal volume $\phi_{\mathrm{v}}^{0}$ at infinite dilution, partial molal adiabatic compressibility $\phi^{0}{ }_{\mathrm{Ks}}$ at infinite dilution, transfer volume $\Delta \phi_{(\mathrm{tr})}$, experimental slopes $S_{\mathrm{v}}$ and $S_{\mathrm{Ks}}$, Falkenhagen coefficient A and Jones-Dole B coefficient. The results are discussed in terms of the dehydration effect of the sodium bromide upon the amino acids and weak solute- solute and strong solute- solvent interactions. The properties of these amino acids in water and water + sodium bromide solution systems are discussed in terms of the charge, size and hydrogen bonding effect.
\end{abstract}

Keywords: L- Valine and L- Phenylalanine; Aqueous Sodium Bromide; Partial Molal Volume; Partial Molal Adiabatic Compressibility at Infinite Dilution; Transfer Volume; A and B Coefficients.

Cite This Article: Dr. Yasmin Akhtar. (2017). "INTERACTION STUDIES OF AMINO ACIDS IN AQUEOUS SODIUM BROMIDE SOLUTIONS AT DIFFERENT TEMPERATURE." International Journal of Research - Granthaalayah, 5(10), 160-167. https://doi.org/10.29121/granthaalayah.v5.i10.2017.2292.

\section{Introduction}

We present in this paper, the study of interaction between L- Valine and L- Phenylalanine in aqueous sodium bromide solution. Ultrasonic investigation in aqueous solution of electrolytes and non-electrolytes with amino acids provides useful information of liquid systems, because intermolecular and intramolecular association, complex formation and related structural changes affect the compressibility of the system. There has been an increased interest in the physicochemical properties of amino acids in aqueous as well as aqueous electrolyte media to understand the role played by the biological molecules in living organism [1-6]. Amino acids have zwitter- ion and are the constituents of the most important class of biopolymers, i.e. Proteins. Disarrangement water and electrolyte balance in living systems cause a wide variety of 
health problems. In physiological media such as blood, membranes, cellulose fluids etc., the dipolar character of amino acids (in presence of ions such as $\mathrm{Na}^{+}, \mathrm{K}^{+}, \mathrm{Mg}^{+2}$ and $\mathrm{Cl}^{-}$etc., dissolved in body water) has an important bearing on their biological functions. Amino acids are the chemical units or "building block" of the body that make up the proteins. All naturally occurring amino acids are L-amino acids which can be metabolized by our enzymes. L- valine is a branched chain amino acids which is important for supplying energy to muscles. The branched chain amino acids enhance energy, increase endurance and aid in muscle tissue recovery and repair [7]. The L-phenylalanine is used for depression attention deficit- hyperactivity disorder (ADHD). Parkinson's disease chronic pain, osteoarthritis, rheumatoid arthritis alcohol withdrawal symptoms and skin disease called vitiligo[8]. In recent years, a number of workers have utilized density and viscosity data to deduce the thermodynamic properties (relative viscosity, Jones -Dole coefficient and free energy of activation of viscous flow) for a number of mixtures solutions [9]. Structural interactions of non-ionic solutes with ionic ones in different solvents are important in many fields of chemistry and bio-chemistry. Very recently, we have made systematic effort to investigate the ultrasonic and volumetric properties of glycerin and dextrose in $\mathrm{Na}_{2} \mathrm{CO}_{3}$ and $\mathrm{NaHCO}_{3}$ buffer solutions and amino acids in concentrated aqueous electrolytic solutions. The study of interaction between $\mathrm{NaCl}, \mathrm{KCl} \mathrm{CaCl} 2$ and $\mathrm{MgCl}_{2}$ electrolytes and aqueous glucose and mannose [10-12]. The thermodynamic parameters were utilized to study of various interactions taking place in the solutions of these ternary systems were measured at 308 and $313 \mathrm{~K}$. It was found that $\mathrm{NaCl} \mathrm{CaCl} 2$ and $\mathrm{MgCl}_{2}$ and $\mathrm{MgCl}_{2}$ increase the apparent molar volume and decrease the adiabatic compressibility of electrolytes solution. This increase could be attributed to the interactions of the ions of the $\mathrm{NaCl}, \mathrm{KCl} \mathrm{CaCl}{ }_{2}$ and $\mathrm{MgCl}_{2}$ electrolytes and aqueous glucose and mannose, causing the transfer of hydrated water molecule to the bulk state.

In the present paper, we report densities, $\rho$, ultrasonic velocity $\mathrm{u}$ and viscosities $\eta$ of L- Valine and L- Phenylalanine in aqueous sodium bromide solution $(0.00,0.025$ and 0.050$) \mathrm{m}$ solutions have been determined experimentally at 308 and $313 \mathrm{~K}$. From these experimental data a number of thermodynamic parameters namely, apparent molal volume, $\phi_{\mathrm{v}}$, apparent molal, adiabatic compressibility $\phi_{\mathrm{Ks}}$, partial molal volume $\phi_{\mathrm{v}}^{0}$ and partial molal adiabatic compressibility $\phi_{\mathrm{Ks}}^{0}$ at infinite dilution, transfer volume $\Delta \phi_{(\mathrm{tr})}$, experimental slopes $S_{\mathrm{v}}$ and $S_{\mathrm{Ks}}$,Falkenhagen $A$ and Jones Dole B coefficients respectively have been calculated. These parameters were utilized to study various interactions taking place in L- Valine and L- Phenylalanine in aqueous sodium bromide solution at 308 and $313 \mathrm{~K}$.

\section{Experimental}

\subsection{Chemical and Preparation}

L- Valine and L- Phenylalanine (99.8\% purity) and sodium bromide (99.9\% purity) were procured from Merck and S d Fine Ltd. They were used as such without further purification, after drying over calcium chloride in desiccators for more than 48 hours. The densities, $\rho$, ultrasonic velocity $\mathrm{u}$ and viscosities $\eta$ of the amino acids in aqueous electrolytes solution at various concentrations as well as in triple distilled de-ionized water were measured experimentally. Aqueous solutions of sodium bromide $(0.00,0.025$ and 0.050$) \mathrm{m}$ were prepared and these were used as a solvents to prepare L- Valine and L- Phenylalanine solutions on mass 
basis covering the whole composition range. All the solutions were prepared by mass in dry box and were stored in special air-tight bottles and kept in dark to avoid photo chemical degradation. The weighing was done on an Afcoset ER-120A electronic balance with an accuracy $\pm 0.1 \mathrm{mg}$. 2.2 Measurement of density, ultrasonic velocity and viscosity.

The densities were measured with a single capillary pycnometer (made of Borosil glass) of bulb capacity of $8 \times 10^{-6} \mathrm{~m}^{3}$. The marks of the stems were calibrated using triple distilled water at 308 and $313 \mathrm{~K}$. The pycnometer was kept for about 30 minutes in a thermostatic water bath so that the thermal fluctuation in density was minimized. The viscosity measurements were carried out by Ubbelohde type suspended level viscometer which was first calibrated with triple distilled water. The viscometer was allowed to stand in an electronically controlled thermostatic water bath for 30 minutes to minimize the thermal fluctuation. The time of fall was recorded with a stop -watch of least count $0.1 \mathrm{~s}$. At least three time recorded were obtained, and the average value was used as the experimental flow time. Poiseuille's equation was employed to calculate the viscosity of the amino acid + aqueous $\mathrm{NaBr}$ solutions.

$$
\eta=\frac{\pi \rho h g r 4 t}{81 \mathrm{~V}}=\rho \beta \mathrm{t}
$$

Here $\rho$ is the density of the amino acids with aqueous $\mathrm{NaBr}$ solutions, $\mathrm{h}$ the height of the column in the viscometer, $\mathrm{g}$ is the acceleration due to gravity, $\mathrm{r}$ is the radius of the capillary, 1 the length capillary and $t$ is the time of fall of the solution of volume $\mathrm{V}$. The term $\mathrm{h}, \mathrm{g}, \mathrm{r}, \mathrm{l}$ and $\mathrm{V}$ are constant for a given viscometer therefore these have been replaced by single term $\beta$. The temperature of the water bath was maintained at $30^{\circ} \mathrm{C}$. The ultrasonic velocities in solutions were measured using a single crystal variable path interferometer at $3 \mathrm{MHz}$. The temperature of the test solutions was maintained at 308 and $313 \pm 0.02 \% \mathrm{~K}$ in an electronically controlled thermostatic water bath. The viscosity, density and velocity data were found to be accurate within $\pm 0.1 \%, \pm$ $0.01 \%$ and $\pm 0.10 \%$ respectively.

\section{Results and Discussion}

The densities ultrasonic velocities and viscosities L- Valine and L- Phenylalanine in aqueous sodium bromide solution $(0.00,0.025$ and 0.050$) \mathrm{m}$ in aqueous sodium bromide $0.01 \mathrm{M}$ ) solutions determined at 308 and $313 \mathrm{~K}$. It is observed that densities $\rho$, ultrasonic velocities $u$ and viscosities $\eta$ for all the ternary systems increase with increase in molalities L- Valine and LPhenylalanine. The values of $\rho, \mathrm{u}$ and $\eta$ increase with increase in concentration of amino acids in all the ternary systems under investigation, which appear to be due to hydrophobic properties of solutes i.e. H-bond forming . This may be attributed to the formation of clusters by the amino acids and strong intermolecular forces in the solute. The changes in structure of solvent or solution as a result of $\mathrm{H}$ - bond formation lead to decrease in intermolecular free length [13]. Solute may occupy the interstitial spaces in solvent or get solvated forming new weaker bonds. It was suggested [14-16] that what is experimentally observed for any system, reflects the compromise between the tendency for the ion and the peptide to interact with each other and inclination of the solutes to associate with the solvent.

The viscosity data were used to calculate the relative viscosity using Jones- Dole equation [17] 
$\eta_{\mathrm{rel}}=\eta / \eta_{\mathrm{o}}=\left[1+\mathrm{Am}{ }^{1 / 2}+\mathrm{Bm}\right]$

Where, $\eta$ and $\eta_{0}$ viscosities of the solutions and solvent respectively. $B$, is the Jones- Dole coefficient [17], an empirical constant, and is measure of ion-solvent interaction. Its values depend on the size and shape of the solute particles. The A is the Falkenhagen coefficient [18] which indicates ion-pair electrostatic interactions. They were obtained by a least square treatment as the intercepts and slopes of the linear plots of $\eta / \eta_{0^{-}} 1 / \mathrm{C}^{1 / 2}$ versus $\mathrm{Cl}^{1 / 2}$ and their values are given in Table 2 .

The viscosity, $\eta$, of dilute solution of non-electrolytes is represented by

$\eta=\eta_{0}(1+B C)$

For a dilute solution of unsolvated spherical colloidal suspension, has derived by Einstein relation

$\eta_{\mathrm{rel}}=1+2.5 \varphi$

Where $\varphi$ is the volume fraction of the solute [19] . If this equation is valid or amino acids, Eq. (3) becomes

$\eta_{\mathrm{rel}}=1+0.0025 \mathrm{~V}_{\mathrm{h}} \mathrm{C}$

Where $\mathrm{V}_{\mathrm{h}}$ is the hydrodynamic volume. Since $\mathrm{Am}^{1 / 2}$ term in Eq. 2 can be assumed to be negligible in a dilute solution, the following relation holds

$\mathrm{B}=0.0025 \mathrm{~V}_{\mathrm{h}}$

Hakin et.al [20] may be assumed that the partial molar volume at infinite dilution of the unsolvated solute particle in a continuum solvent. The more B values in the mixed solvent might mean a more hydrodynamic volume in the mixed solvent.

A perusal of Table 1 shows that the values of A coefficients are negative ion-ion interactions and characteristics of a ions associated size and shape of the ions and thereby suggesting the ion-ion interactions are weak for L- Valine and L- Phenylalanine in aqueous sodium bromide ternary systems. The B-coefficient are positive for all these ternary systems and ion-solvent interactions are strong. The positive value of B with electrolytes concentration of water molecules as a result of shielding of polar terminal groups of L- Valine and L- Phenylalanine molecules is due to increased interaction between these polar ends and ions of the electrolytes. Iqbal et al [21] have estimated that the contraction of water around the appositively charged group is caused by electrostatic ion- solvent interaction and is called as electrostriction. Table 1 shows that the values of $\mathrm{B}$ are positive which indicates strong solute- solvent interactions. The coefficient $\mathrm{B}$ values are in the order:

L- Valine + aqueous $\mathrm{NaBr}>\mathrm{L}$ - Phenylalanine + aqueous $\mathrm{NaBr}$ 
The hydration behavior of amino acids considered the following interactions:

1) The terminal groups of zwitter-ions of amino nature which may hydrophobic , hydrophilic or amphiphilic, acids , $-\mathrm{NH}_{3}{ }^{+}$and $\mathrm{COO}^{-}$are hydrated in electrostatic manner whereas hydration of intervening backbone depends on its.

2) The overlap of hydration groups co spheres of terminal $\left(-\mathrm{NH}_{3}{ }^{+}\right.$and $\left.\mathrm{COO}^{-}\right)$

And the adjacent groups result in volume change.

3) Electrostriction of $\mathrm{NH}_{3}^{+}$group is greater than the COOby a factor of 10.

The apparent molal volume, $\phi_{\mathrm{v}}$ were calculated from measured density data of L- Valine and LPhenylalanine in aqueous sodium bromide ternary systems using the following equation:

$\phi_{v}=\left[1000\left(\rho^{0}-\rho\right) / m \rho \rho^{0}\right]+M / \rho$

Where $M$ is the mean molecular mass of the solutes, $\rho^{0}$ and $\rho$ are densities of solvent and solution. In these cases where molality dependence of $\phi_{\mathrm{v}}$, having definite trend points..

The partial molal volume at infinite dilution $\phi^{\circ}{ }_{\mathrm{v}}$ was calculated by taking an average data points. The linear variation is obtained by least square fitting to the following equation.

$\Phi_{\mathrm{v}}=\phi^{0}{ }_{\mathrm{v}}+\mathrm{S}_{\mathrm{v}} \mathrm{m}^{1 / 2}$

The intercept which is the apparent molal volume at infinite dilution $\phi^{0}{ }_{\mathrm{v}}$ and the experimental slope, $S_{v}$ which is considered to be volumetric pair wise coefficient. The derived values $\phi^{0}{ }_{v}$ of along with $S_{v}$ are summarized in Table 2. Table 2 shows that the values of $\phi^{0}{ }_{v}$ are positive of these ternary systems which indicates ion-solvent interactions are strong. The $\phi^{0}{ }_{v}$ values increase due to reduction in the electrostriction effect at terminals, $\left(-\mathrm{NH}_{3}{ }^{+}\right.$and $\left.\mathrm{COO}\right)$ it makes disruption of side group hydration by that of the charge end which is in good agreement with the results reported in glucose - alcohol - water mixture [13]. The negative $S_{v}$ values which indicates the presence of weak ion-ion interactions and less complex formation taking place in theses ternary systems.

The transfer volume, $\Delta \phi^{0}{ }_{v(t r)}$ at infinite dilution of L- Valine and L- Phenylalanine in Aqueous sodium bromide ternary systems were calculated from the following equation:

$\Delta \phi^{0}{ }_{(\mathrm{tr})}=\phi_{\mathrm{v}(\mathrm{aq} \text { electrolytes })}^{0}-\phi_{\mathrm{v}(\mathrm{aq})}^{0}$

The transfer volume, $\Delta \phi^{0}{ }_{\mathrm{v}(\mathrm{tr})}$ can be explained on the basis of co-sphere overlap model in terms of solute-solute. These values are also presented in Table 2, which shows to be positive for these ternary systems. The change in values of $\Delta \phi_{\mathrm{v}(\mathrm{tr})}^{0}$ are interpreted on the basis of co-sphere overlap model was given by Friedman and Krishnan[23]. According to this model, hydrophilic-ionic group interactions contribute positively, whereas, hydrophilic-hydrophobic interaction contribute negatively to the $\Delta \phi^{0}{ }_{\mathrm{v}(\mathrm{tr})}$ values.

The overlap of co-solute-ions and amino acids comes into interactions between them:

- The $\left(-\mathrm{NH}_{3}{ }^{+}\right.$and $\left.\mathrm{COO}^{-}\right)$charged end of amino acid and ions of co-solute (electrolytes).

- Hydrophilic/hydrophobic interactions take place between amino acid and solvent (aqueous electrolytes). 
As amino acid exist zwitter-ion in pure and there is an overall decrease in volume of water due to electrostriction of water near the end group. The observed $\Delta \phi^{0}{ }_{\mathrm{v}(\mathrm{tr})}$ values suggest that the ionhydrophilic and hydrophilic -hydrophobic interaction taking place in these ternary systems.

The density and adiabatic compressibility values were employed for calculated apparent molal adiabatic compressibility, $\phi \mathrm{K}_{\mathrm{s}}$ of L- Valine and L- Phenylalanine in aqueous sodium bromide ternary solution at different molality and at 308 and $313 \mathrm{~K}$ using the equation.

$\phi K_{s}=\left[1000\left(\rho^{0} K_{s}-\rho K_{s}^{0}\right) / m \rho \rho^{0}\right]+M K_{s} / \rho$

Where $\mathrm{K}_{\mathrm{s}}{ }^{0}$ and $\mathrm{Ks}$ are adiabatic compressibility of solvent and solution. In these cases where molality dependence of $\phi \mathrm{K}_{\mathrm{s}}$, having definite trend points. The less negative values of $\phi \mathrm{K}_{\mathrm{s}}$ over the entire range of molality of the ternary systems which indicates strong solute-solvent interactions.

The partial molal adiabatic compressibility, $\phi^{\circ} \mathrm{K}_{\mathrm{s}}$ at infinite dilution are obtained from the plot of $\phi K_{\mathrm{s}}$ versus $\mathrm{m}^{1 / 2}$ by least square method. The molality dependence of this parameter has been expressed in terms of the following equation.

$\phi_{\mathrm{Ks}}=\phi_{\mathrm{Ks}}^{0}+\mathrm{S}_{\mathrm{Ks}} \mathrm{m}^{1 / 2}$

Where $\phi^{0}{ }_{\mathrm{Ks}}$ is the partial molar adiabatic compressibility at infinite dilution. It provides information regarding solute-solvent interaction. $\mathrm{S}_{\mathrm{Ks}}$ is the experimental slope. The values of $\phi_{\mathrm{Ks}}^{0}$ and $\mathrm{S}_{\mathrm{Ks}}$ are also included in Table 3 . Table 3 shows that the less negative values of $\phi^{0}{ }_{\mathrm{Ks}}$ over the entire range of molality of the ternary systems which indicates strong solute-solvent interactions. The less negative values of $\phi \mathrm{K}_{\mathrm{s}}$ are due to loss of structural compressibility of solvent on increase in the population of four bonded solvent molecule in the vicinity of the solute molecules. The values of $\mathrm{S}_{\mathrm{Ks}} \mathrm{L}-\mathrm{Valine}+$ water+ $\mathrm{NaBr}$ and $\mathrm{L}-$ Phenylalanine + water+ $\mathrm{NaBr}$ are negative which is indicating the presence of weak ion-pair interactions. From this tabulation, one can notice that the values of in mixed ternary system less than the pure system suggesting the weak interactions in the ternary systems by others [22].

Table 1: The Falkenhagen coefficient, (A), Jones Dole coefficient, (B), of L- Valine and LPhenylalanine in aqueous $\mathrm{NaBr}$ solution at 308 and $313 \mathrm{~K}$

\begin{tabular}{|c|c|c|c|c|}
\hline $\mathbf{~ m ~ ( m o l ~ I ~}$ & $\mathbf{A})$ & $\mathbf{A}\left(\mathbf{d m}^{\mathbf{3} / 2} \mathbf{m o l}^{-\mathbf{1 / 2}}\right)$ & \multicolumn{2}{c|}{$\mathbf{B}\left(\mathbf{d m}^{\mathbf{3}} \mathbf{~ m o l}^{\mathbf{- 1}}\right)$} \\
\hline & 308 & 313 & 308 & 313 \\
\hline & \multicolumn{4}{|c|}{ L- Valine + aqueous NaBr } \\
\hline 0.000 & -0.0972 & 0.0828 & 1.1192 & 1.1739 \\
\hline 0.025 & -0.0973 & -0.1634 & 0.9271 & 1.7504 \\
\hline 0.050 & -0.0832 & 0.0984 & 1.1586 & 0.6977 \\
\hline & \multicolumn{4}{|c|}{ L- Phenylalanine + aqueous NaBr } \\
\hline 0.000 & -0.0860 & 0.0990 & 0.5013 & 0.7539 \\
\hline 0.025 & -0.0876 & -0.0146 & 1.5160 & 1.3142 \\
\hline 0.050 & -0.1164 & -0.1538 & 1.3995 & 0.7763 \\
\hline
\end{tabular}


Table 2: The partial molal volume $\phi^{0}{ }_{\mathrm{v}}$, at infinite dilution, experimental slope $S_{\mathrm{v}}$ and transfer volume $\Delta \phi_{(\text {tr })}$, of L- Valine and L- Phenylalanine in aqueous $\mathrm{NaBr}$ solution at 308 and $313 \mathrm{~K}$

\begin{tabular}{|c|c|c|c|c|c|c|}
\hline \multirow[t]{2}{*}{$\mathrm{m}\left(\mathrm{mol} \mathrm{I}^{-1}\right)$} & \multicolumn{2}{|c|}{$\begin{array}{c}\phi_{v}^{0} \\
\left(\mathrm{~m}^{3} \mathrm{~mol}^{-1}\right)\end{array}$} & \multicolumn{2}{|c|}{$\begin{array}{c}S_{\mathrm{v}} \\
\left(\mathrm{dm}^{3} \mathrm{~mol}^{-1}\right)\end{array}$} & \multicolumn{2}{|c|}{$\begin{array}{c}\Delta \boldsymbol{\phi}_{(\mathrm{tr})} \\
\left(\mathbf{m}^{\mathbf{3}} \mathbf{m o l}^{-\mathbf{1}}\right)\end{array}$} \\
\hline & 308 & 313 & 308 & 313 & 308 & 313 \\
\hline & \multicolumn{6}{|c|}{ L- Valine + aqueous $\mathrm{NaBr}$} \\
\hline 0.000 & 44.32 & 42.76 & -86.76 & -134.12 & - & - \\
\hline 0.025 & 17.41 & 13.81 & -121.11 & -262.37 & 26.96 & 46.54 \\
\hline \multirow[t]{2}{*}{0.050} & 13.81 & 10.96 & -126.12 & -185.57 & 30.52 & 35.82 \\
\hline & \multicolumn{6}{|c|}{ L- Phenylalanine + aqueous $\mathrm{NaBr}$} \\
\hline 0.000 & 56.38 & 55.72 & -105.05 & -103.64 & - & - \\
\hline 0.025 & 54.79 & 56.60 & -63.77 & -43.72 & 1.59 & 6.87 \\
\hline 0.050 & 11.09 & 39.20 & -159.40 & -71.32 & 45.30 & 16.50 \\
\hline
\end{tabular}

Table 3: The apparent molal adiabatic compressibility $\phi^{0}{ }_{\mathrm{Ks}}$ at infinite dilution and experimental slope, $\mathrm{S}_{\mathrm{Ks}}$ of L- Valine and L- Phenylalanine in aqueous $\mathrm{NaBr}$ solution at 308 and $313 \mathrm{~K}$

\begin{tabular}{|c|c|c|c|c|}
\hline \multirow[t]{2}{*}{$\mathrm{m}\left(\mathrm{mol} \mathrm{I}^{-1}\right)$} & \multicolumn{2}{|c|}{$\begin{array}{c}\phi_{\mathrm{Ks}}^{0} \times 10^{-7} \\
\left(\mathrm{~m}^{2} \cdot \mathrm{N}^{-1}\right)\end{array}$} & \multicolumn{2}{|c|}{$\begin{array}{r}\mathrm{S}_{\mathrm{Ks}} \times \mathbf{1 0}^{-7} \\
\left(\mathrm{~N}^{-1} \mathrm{~m}^{-1} \mathrm{~mol}^{-1}\right)\end{array}$} \\
\hline & 308 & 313 & 308 & 313 \\
\hline & \multicolumn{4}{|c|}{ L- Valine + aqueous NaBr } \\
\hline 0.000 & -1.05 & -0.94 & -1.21 & -1.73 \\
\hline 0.025 & -0.96 & -0.85 & -0.97 & -1.70 \\
\hline \multirow[t]{2}{*}{0.050} & -0.64 & -0.64 & -1.67 & -1.90 \\
\hline & \multicolumn{4}{|c|}{ L- Phenylalanine + aqueous $\mathrm{NaBr}$} \\
\hline 0.000 & -1.04 & -1.09 & -1.17 & -0.81 \\
\hline 0.025 & -0.87 & -1.07 & -1.53 & -0.41 \\
\hline 0.050 & -0.51 & -0.95 & -2.12 & -0.44 \\
\hline
\end{tabular}

\section{Conclusion}

In the present work the molecular and ion-solvent interaction are strong and ion -ion interactions are weak of L- Valine + water+ $\mathrm{NaBr}$ and $\mathrm{L}-$ Phenylalanine + water+ $\mathrm{NaBr}$ at 308 and $313 \mathrm{~K}$. The presence of ion-solvent or ion-ion interaction resulting in attractive force promotes the structure making tendency. We conclude from the B coefficient that L- Valine shows stronger ion solvent interaction than L- Phenylalanine molecules is due to increased interaction between these polar ends and ions of the electrolytes. The molecular interactions values are in the order:

$$
\text { L- Valine + aqueous } \mathrm{NaBr}>\mathrm{L} \text { - Phenylalanine }+ \text { aqueous } \mathrm{NaBr}
$$

\section{Acknowledgement}

I am highly thankful to Dr. Nadia Hussain to provide the laboratory facilities for research Department of Chemistry, University of Tabuk, K.S.A 


\section{References}

[1] Y. Akhtar, S. F. Ibrahim, Arabian J. Chem. 4 (2011) 487-490

[2] F. J. Millero, A. L. Surdo and C. Shiv, J. Phys. Chem. 87 (1978) 784.

[3] Vishnu D., Y. Akhtar, J. D.Pandey, Acta Acoust. 84(1998) 976.

[4] Y. Akhtar, Fluid Phase Equil. 258 (2007)125.

[5] X. Jiang, C. Zhu and Y. Ma, J. Chem. Thermodyn. 71(2014)50-63.

[6] M. S. Hussain, T.K Kabriaz, M. N. Islam and M. E. Haque, J. Chem. Thermodyn. 71 (2014)6-13.

[7] Riyazuddin and M. A. Usmani, Thermochemica. Acta, 527 (2012), 112-117.

[8] C. Zhu and X. Jiang, Y. Ma, J. Chem. Thermodyn. 71(2014)50-63.

[9] Yasmin Akhtar, J. International Academic Research Multidis. 2 (5) (2014) 694-700.

[10] Yasmin Akhtar, International Journal "Advanced Materials Research, 1051(2014) 215-220.

[11] Y. Akhtar, Indian J. Res. 5(8)2016, 287-292.

[12] Y. Akhtar, Chemical Sci. International J. 17 (2) (2016) 1-7.

[13] T. S. Banipal and G. Singh Indian J. Chem. 3A (2000)1011.

[14] A. P. Mishra and Gautum S. K. , Indian J. Chem. 40A (2001), 100 and D. L. Q. Yu, Y. Y. Wang and D. Sun Indian J. Chem. 41A (2002)1126.

[15] R. J. Laurich, C. R. Torok and M. J. Tubergen J. Phys. Chem.A 106 (2002)8013.

[16] K. Karl, B. Alex and N. Kishore, J. Chem . Thermodyn. 34 (2002) 319.

[17] G. Jones and M. Dole, J. Am. Chem. Soc. 51 (1929) 2950.

[18] H. Fakenhagen and E. L. Vernon, Z. Phys. 33 (1932) 140.

[19] M. J. Lee, T. K. Lin, J. Chem. Eng. Data 45(1995) 336-341.

[20] A. W. Hakin, M. M. Duck, J. L. Marty, K. E. Preuss, J. Chem. Soc. Faraday Trans. 90 (1994)2027-2037.

[21] M. Iqbal, M. Mateullah Can. J. Chem. 68 1990)7.

[22] A. P. Mishra and S. K. Gautam, Indian J. Chem. 40A (2001) 100.

[23] H. L. Friedman and C. V. Krishnan, water a comprehensive Treatise, vol. 3 New York, 1973.

*Corresponding author.

E-mail address: dryasminakhtar2004 @yahoo.com 